\title{
Cross-cultural adaption and validation of the Swedish version of the Core Outcome Measures Index for low-back pain
}

\author{
Hannah Granström ${ }^{1} \cdot$ Anna Langborg $^{1} \cdot$ Anne F. Mannion $^{3} \cdot$ Eva Rasmussen-Barr $^{1,2}$ (i)
}

Received: 22 September 2019 / Revised: 22 September 2019 / Accepted: 24 December 2019 / Published online: 4 January 2020

(c) The Author(s) 2020

\begin{abstract}
Purpose There is a wide selection of instruments and questionnaires available, but many are time consuming in their administration, for patients, practitioners and researchers alike. The Core Outcome Measures Index (COMI) is a short, selfadministrated, multidimensional instrument translated into several languages that covers five domains recommended in the assessment of outcome in patients with low-back pain. The purpose of this study was to cross-culturally adapt the COMI from English to Swedish and to test the face and construct validity and reproducibility of its results in patients with low-back pain. Methods Participants $(n=102)$ were included from primary and secondary care. The participants reported moderate pain and disability levels. All participants filled in the COMI, the Oswestry Disability Index and the EQ5D at baseline. Forty-nine filled in the COMI again after 7 days for the reproducibility part of the study.

Results The instrument was successfully forward and back-translated. In the validation process, there were low floor/ceiling effects, with the exception of the symptom-specific well-being (floor) and work disability (ceiling) items. The specific COMI domains and whole score correlated significantly with the chosen reference scale scores to the hypothesised extent (Rho 0.30-0.60 and $>0.60$ respectively). COMI reached ICC 0.63 (95\% CI 0.42-0.77) in the reproducibility test and the separate items, ICC 0.41-0.78.

Conclusions The Swedish COMI shows acceptable psychometric properties and is thus suitable to use as a short instrument for measuring important domains in patients with low-back pain. A future study should investigate the instrument's sensitivity to measure change after treatment.
\end{abstract}

\section{Graphic abstract}

These slides can be retrieved under Electronic Supplementary Material.
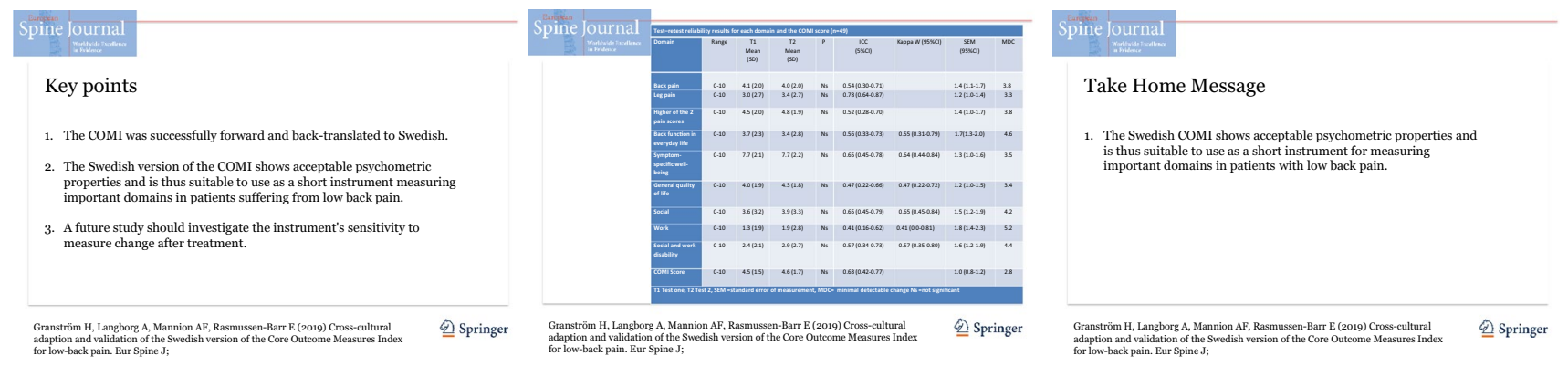

Keywords COMI $\cdot$ Reproducibility of results $\cdot$ Rehabilitation $\cdot$ Instrument $\cdot$ Clinometric

Electronic supplementary material The online version of this article (https://doi.org/10.1007/s00586-019-06271-z) contains supplementary material, which is available to authorized users.

Eva Rasmussen-Barr

eva.rasmussen.barr@ki.se

Extended author information available on the last page of the article 


\section{Introduction}

Low-back pain (LBP) still is the number one disorder worldwide for years lived with disability [1]. Thus, people suffering from LBP are amongst those most commonly seeking health care. The availability of reliable and valid PROMs enables practitioners to assess and evaluate pain, function and quality of life (QOL) in a standardised manner [2]. PROMs may also act as a tool to identify the effectiveness of LBP interventions when used on a larger scale [2].

In 1996, a multinational group of back pain researchers called for the use of standardised and easily administered outcome measures in patients with LBP [3]. They recommended assessment of the most important domains including pain, function, generic health status/well-being, disability and patient satisfaction. Items covering these domains were extracted from widely used PROMs resulting in a new core set of six items [3]. The initial core set showed satisfactory reliability and validity [4, 5], and was further developed with the addition of a seventh item to cover general quality of life, resulting in the Core Outcome Measurement Index (COMI), a self-administrated and multidimensional PROM [6].

The items finally included in the COMI include back pain and leg pain intensity, function in everyday life, symptomspecific well-being, general quality of life and social and work disability. The COMI has been shown to be a valuable instrument and been recommended for further use as a standardised outcome measure in clinical practice, clinical trials, multi-centre studies and surgical registries [7]. It is short, easy to administer, and to date has been translated and cross-cultural adapted into several different languages; Brazilian-Portuguese [8], Chinese [9], French [10, 11], Hungarian [12], Italian [13], Japanese [14], Korean [15], Norwegian [16] and Polish [17]. So far, the COMI has been used as an outcome measure in several clinical studies [18-20] and in the International EUROSPINE Spine Tango registry [21].

The COMI has not yet been adapted for the Swedish language. Therefore, this study aimed to translate and crossculturally adapt the COMI from English to Swedish, and to assess its reproducibility and validity in patients with LBP.

\section{Methods}

The study was conducted in two stages. The first stage involved the translation and cross-cultural adaption of the COMI from English to Swedish in accordance with stated guidelines [22].The second stage involved evaluation of the instrument's face and construct validity along with the reproducibility of results through test-retest in Swedish primary and secondary health care settings. The regional Ethical Committee in Stockholm approved the study (Dnr: 2015/1866-32).

\section{The Core Outcome Measures Index}

The COMI covers five different domains, with seven individual items; pain intensity (two separate items measuring back pain and leg/buttock pain), back function in everyday life (one item), symptom-specific well-being (one item), general quality of life (one item) and disability (two separate items measuring social disability and work disability).

The composite COMI score (range 0-10) is calculated using the average score of the five domains. Higher COMI scores indicate worse status. For the domain pain intensity, the data are collected using $0-10$ graphic rating scales, with the higher of the two values for back pain and leg/buttock pain being used to represent the "pain" domain. Five-point scales (1-5) are used for the remaining domains, with the scores being rescaled into a 0 to 10 -point range (score (1-5) minus 1 , multiplied by 2.5 ). The values for the two disability items are averaged to represent the "disability" domain [5]. Averages of the five domains form the COMI (0-10, best-worst).

\section{Translation and cross-cultural adaption}

The translation and cross-cultural adaption was carried out according to recommended guidelines for health status measures [22]. Two native-speaking Swedish persons (one expert T1 and one naïve T2) who were fluent in English completed a forward translation from English to Swedish. All translators and the expert group consisting of three physiotherapists (two researchers/clinicians and one clinician) synthesised the results of the translation resulting in a common translation (T-12). In the process, it was considered important that consensus resolved the issues and not one person's opinion. The T-12 version was then back-translated from Swedish to English by two translators (BT1 and BT2) fluent in Swedish but with English as their mother tongue. Back translation highlights inconsistencies or conceptual errors in the translation. The same expert group as before, with addition of the PROMs developer, consolidated all versions (the original, T1, T2, T-12, BT1 and BT2) and developed the pre-final version of the Swedish COMI for field-testing. 


\section{Test of pre-final version (face validity)}

Ten participants were asked to verbalise their thoughts about the questions whilst completing the COMI. The participants were asked whether they fully understood the questions and their implications and whether the wording seemed clear. If any item seemed unclear, the participant was asked by the observer (AL) to rephrase it in order to improve readability and understanding.

\section{Study population}

Patients with a primary complaint of LBP, with or without leg pain $>3$ months, and with a good understanding of the Swedish language were consecutively recruited at a physiotherapy primary health care clinic with direct access to physiotherapists, and an orthopaedic surgery clinic with patients being considered for spinal surgery (decompression for spinal stenosis, surgery for disc hernia or spinal fusions). The exclusion criteria were pregnancy and "red flags" such as fracture, cancer and inflammatory disease. Written informed consent was obtained from all participants. One-hundred-two participants were included in the validity study and 49 of those were included in the test-retest analysis (Table 1). The study sample size was determined according to the recommendations [23].

At their first visit to either of the clinics, all participants completed the COMI, the reference scales and questions concerning socio-demographic variables. The chosen reference scales were Oswestry Disability Index (ODI) [24] and the EuroQol-5 Dimensions Index (EQ5D) [25]. The ODI is a spine specific PROM assessing LBP-related disability using 10 questions rated from 1-5 and transformed to a score of 0 (no disability) to maximum 100 for worst disability [24]. The EQ5D is a generic instrument measuring Health Related Quality of Life and comprises 5 items concerning mobility, self-care, usual activities, pain/discomfort and anxiety/depression [25]. We used the 3-level version of the EQ5D in which each item is rated on a 3-point adjectival scale. To calculate the EQ5D Index, the time trade-off valuation technique (TTO) was used (https ://euroqol.org/docs/EQ-5D-3L-User-Guide.pdf).

\section{Statistical analysis}

\section{Floor and ceiling effects}

Floor (worst status) and ceiling (best status) effects were evaluated and considered to be present if more than $15 \%$ of the patients reported the highest or the lowest possible score, respectively [26].
Table 1 Demographic characteristics and clinical status of included participants $(n=102)$

\begin{tabular}{lll}
\hline & $\begin{array}{l}\text { Validity } \\
n=102\end{array}$ & $\begin{array}{l}\text { Test-retest } \\
n=49\end{array}$ \\
\hline Sex, $n$ (\% female) & $53(52)$ & $31(63)$ \\
Age (mean, SD) & $51(14)$ & $55(14)$ \\
Recruited from, $n(\%)$ & & \\
Primary health care & $62(61)$ & 49 \\
Secondary care & $40(39)$ & - \\
Employment status, $n(\%)$ & & \\
Working & $55(54)$ & $26(53)$ \\
Sick-listed & $12(12)$ & $2(4)$ \\
Pension & $27(26)$ & $18(37)$ \\
Working and sick-listed & $6(6)$ & $2(4)$ \\
Missing data & $2(2)$ & $1(2)$ \\
Duration of back pain, $n(\%)$ & & \\
$<6$ months & $25(24)$ & $11(22)$ \\
6-12 months & $11(11)$ & $5(10)$ \\
$>12$ months & $66(65)$ & $33(67)$ \\
Previous episodes of back pain & $81(79)$ & $39(79)$ \\
Only back pain, $n(\%)$ & $50(49)$ & $31(63)$ \\
Back pain VAS (0-10), mean (SD) & $4.3(2.4)$ & $4.5(1.9)$ \\
EQ5D, mean (SD) & $0.59(0.29)$ & $0.65(0.20)$ \\
EQ5D VAS, mean (SD) & $55.9(20.7)$ & $63.0(17.0)$ \\
ODI, mean (SD) & $30.2(16.7)$ & $25.4(11.9)$ \\
COMI score, mean (SD) & $5.2(2.1)$ & $4.5(1.5)$ \\
\hline
\end{tabular}

VAS visual analogue scale, ODIOswestry Disability Index, EQ5DEuroQol-5 Dimensions Index

\section{Construct validity}

Analysis of the construct validity was carried out in relation to predefined hypotheses, based on the findings of previous studies in which the COMI was cross-culturally adapted. Specifically, the hypotheses were that each of the specific COMI domains would correlate at least moderately $(r=0.30-0.60)$ with the composite scores of the two reference scales (Table 2). We hypothesized that the COMI score would correlate highly $(r>0.60)$ with the composite score of the reference scales.

Spearman's Rank correlation coefficients (Rho) were used in all correlation analyses due to the variety in scale types. The coefficients were described as low $(<0.3)$, moderate $(0.3-0.6)$ and high $(>0.6)[16]$.

\section{Reproducibility of results}

A test-retest analysis was completed for the specific COMI items and the COMI score, with 7 days between the tests [23]. The first assessment was carried out at the clinic. The participants were given the second questionnaire in a prepaid envelope, to fill in and to send to or leave at the clinic 
Table 2 Construct validity with prior formulated hypotheses and floor/ceiling effects $(n=102)$

\begin{tabular}{|c|c|c|c|c|}
\hline COMI domains/index & Hypothesis & $\begin{array}{l}\text { Correlation value } \\
\text { (Rho) }\end{array}$ & $\begin{array}{l}\text { Floor effect } \\
(\%)\end{array}$ & $\begin{array}{l}\text { Ceiling } \\
\text { effect } \\
(\%)\end{array}$ \\
\hline Back Pain & Moderate correlation with the EQ5D and ODI full score & $\begin{array}{l}\text { EQ5D }-0.40 \\
\text { ODI } 0.33\end{array}$ & 0 & 2 \\
\hline Leg/buttock pain & Moderate correlation with the EQ5D and ODI full score & $\begin{array}{l}\text { EQ5D }-0.51 \\
\text { ODI } 0.59\end{array}$ & 0 & 16 \\
\hline Higher of the two pain scores & Moderate correlation with the EQ5D and ODI full score & $\begin{array}{l}\text { EQ5D }-0.65 \\
\text { ODI } 0.60\end{array}$ & 0 & 0 \\
\hline Back function in everyday life & Moderate correlation with the EQ5D and ODI full score & $\begin{array}{l}\text { EQ5D }-0.57 \\
\text { ODI } 0.61\end{array}$ & 11 & 13 \\
\hline Symptom-specific well-being & Moderate correlation with the EQ5D and ODI full score & $\begin{array}{l}\text { EQ5D }-0.46 \\
\text { ODI } 0.41\end{array}$ & 48 & 1 \\
\hline General quality of life & Moderate correlation with the EQ5D and ODI full score & $\begin{array}{l}\text { EQ5D }-0.59 \\
\text { ODI } 0.59\end{array}$ & 10 & 4 \\
\hline Social disability & Moderate correlation with the EQ5D and ODI full score & $\begin{array}{l}\text { EQ5D }-0.45 \\
\text { ODI } 0.54\end{array}$ & 20 & 20 \\
\hline Work disability & Moderate correlation with the EQ5D and ODI full score & $\begin{array}{l}\text { EQ5D }-0.73 \\
\text { ODI } 0.47\end{array}$ & 12 & 54 \\
\hline Social and work disability & Moderate correlation with the EQ5D and ODI full score & $\begin{array}{l}\text { EQ5D }-0.60 \\
\text { ODI } 0.65\end{array}$ & 12 & 18 \\
\hline COMI composite score & High correlation with the EQ5D and ODI full score & $\begin{array}{l}\text { EQ5D }-0.73 \\
\text { ODI } 0.72\end{array}$ & 0 & 0 \\
\hline
\end{tabular}

Coefficients (Rho) described as low $(<0.3)$, moderate $(0.3-0.6)$ and high $(>0.6)$, ODIOswestry Disability Index, EQ5DEuroQol-5 Dimensions Index

after 7 days. The participants were prompted by a text message to fill in the COMI a second time. No treatment was scheduled between the two tests. To study differences in values between test 1 and 2, Wilcoxon's matched pairs test was used.

The reproducibility of the specific COMI domains and the COMI score was assessed with the Intraclass Correlation Coefficient $\left(\mathrm{ICC}_{2,1}\right)$ using a two-way random effects model. ICC can range from 0 to 1 , and values were considered good if ICC was 0.60-0.80 and excellent if $>0.80$ [27]. The domains back function in everyday life, symptom-specific well-being, general quality of life, social and work disability were also analysed by means of Kappa values with quadratic weighting. The response options for these items are categorical and the categories are ordinal. Reliability estimates were interpreted as less than $0.40=$ poor, $0.40-0.59=$ moderate, $0.61-0.80=$ substantial, and more than $0.81=$ excellent [28]. Agreement was given by the standard error of measurement (SEM) and minimal detectable change (MDC) where MDC is the minimal amount of change in a patient's score that with $95 \%$ certainty is not likely to be due to error [23].

$\mathrm{R}$ package version 1.3.1 was used for the statistical analyses [29].

\section{Results}

\section{Cross-cultural adaption of the COMI}

The Swedish version of the COMI is presented in Appendix 1 in ESM. COMI was successfully forward- and backtranslated into Swedish with neither semantic nor language ambiguities, and all items were approved by the expert group. Pre-testing of the preliminary Swedish COMI revealed no ambiguities.

\section{Floor and ceiling effects}

Floor effects were present for the item symptom-specific well-being (48\%) and for social disability (20\%) (Table 2). Notable ceiling effects were present for the items leg pain (16\%), social $(20 \%)$ and work disability (54\%). When analysing the higher of the two pain scores from the pain domain, (as used when calculating the composite COMI score), no end effects were shown ( $0 \%$ respectively). When analysing social and work disability together, the ceiling effect was $18 \%$. For the composite COMI score no floor or ceiling effects were seen. We had few missing values $(n=2)$. 


\section{Construct validity}

All predefined hypotheses regarding the relationship between the scores for the specific COMI domains and the scores for the reference instruments were positively confirmed, with moderate to high correlations (Table 2). Back pain showed a lower relationship with the ODI $(r=0.33)$ but in the combined value with leg pain (higher of the two scores) the relationship was stronger $(r=0.60)$. Symptomspecific well-being, showed a lower correlation with the ODI and the EQ5D ( $r=0.41$ and $r=-0.46$, respectively). The composite COMI score showed a high correlation with the EQ5D $(r=-0.73)$ and the ODI full score $(r=0.72)$.

\section{Reproducibility}

The test-retest results are shown in Table 3. No significant differences between test and retest scores were detected for either the specific COMI domains, or the composite COMI. Reliability point estimates suggested a moderate agreement for the domains back function in everyday life $\left(\kappa_{\mathrm{w}}=0.55\right)$, general quality of life $\left(\kappa_{\mathrm{w}}=0.47\right)$, and work disability $\left(\kappa_{\mathrm{w}}=0.41\right)$. For symptom-specific well-being and social disability a substantial reliability was shown $\left(\kappa_{\mathrm{w}}=0.64 / 0.65\right)$. The ICCs for the specific COMI domains were 0.41 to 0.57 except for the item leg pain (0.78). The ICC for the COMI score indicated adequate reproducibility for the instrument $\left(\mathrm{ICC}_{2,1} 0.63,95 \%\right.$ CI $\left.0.42-0.77\right)$. The SEM was 1.0 point and the MDC was 2.8 points for the COMI score.

\section{Discussion}

We cross culturally adapted the COMI for use in Swedish-speaking patients suffering from LBP. In addition, we explored its test-retest reliability. The cross-cultural adaption procedure resulted in a Swedish version of COMI that was considered equivalent to the original English version and our results demonstrated acceptable psychometric properties.

We collected data at a primary and a secondary care clinic and included patients with LBP and with/without leg pain treated either conservatively by physiotherapists or referred to be considered for spinal surgery. The Norwegian study included patients in primary care and suffering from back pain but not leg pain [16]. Other studies have included a variety of hospital samples $[8,10,12,13]$. The diversity in the previous studies, with respect to both the included patients and the reference scales used, makes it somewhat difficult to compare our findings, as results from the analyses may vary due to populations studied.

\section{Floor and ceiling effects}

Our results on floor and ceiling effects showed somewhat diverse effects compared to previous validation studies. There was a notable ceiling effect (best status) for the item leg pain (16\%) and work disability (54\%), and a floor effect (worst status) for the item symptom-specific well-being (48\%). For the composite score no floor or ceiling effects were seen, which concurs with the findings of previous studies. A floor effect for symptom-specific well-being has previously been reported $[8-10,12,13]$. The Hungarian study showed a floor effect of $75.2 \%$ for this item, which might be considered above the critical value of $70 \%$ but might be

Table 3 Test-retest reliability results for each domain and the COMI score $(n=49)$

\begin{tabular}{|c|c|c|c|c|c|c|c|c|}
\hline Domain & Range & $\begin{array}{l}\text { T1 } \\
\text { Mean (SD) }\end{array}$ & $\begin{array}{l}\text { T2 } \\
\text { Mean } \\
\text { (SD) }\end{array}$ & $P$ & $\begin{array}{l}\text { ICC } \\
(95 \% \text { CI })\end{array}$ & Kappa $W(95 \%$ CI $)$ & $\begin{array}{l}\text { SEM } \\
(95 \% \mathrm{CI})\end{array}$ & MDC \\
\hline Back pain & $0-10$ & $4.1(2.0)$ & $4.0(2.0)$ & Ns & $0.54(0.30-0.71)$ & & $1.4(1.1-1.7)$ & 3.8 \\
\hline Leg pain & $0-10$ & $3.0(2.7)$ & $3.4(2.7)$ & Ns & $0.78(0.64-0.87)$ & & $1.2(1.0-1.4)$ & 3.3 \\
\hline Higher of the 2 pain scores & $0-10$ & $4.5(2.0)$ & $4.8(1.9)$ & Ns & $0.52(0.28-0.70)$ & & $1.4(1.0-1.7)$ & 3.8 \\
\hline Back function in everyday life & $0-10$ & $3.7(2.3)$ & $3.4(2.8)$ & Ns & $0.56(0.33-0.73)$ & $0.55(0.31-0.79)$ & $1.7(1.3-2.0)$ & 4.6 \\
\hline Symptom-specific well-being & $0-10$ & $7.7(2.1)$ & $7.7(2.2)$ & Ns & $0.65(0.45-0.78)$ & $0.64(0.44-0.84)$ & $1.3(1.0-1.6)$ & 3.5 \\
\hline General quality of life & $0-10$ & $4.0(1.9)$ & $4.3(1.8)$ & Ns & $0.47(0.22-0.66)$ & $0.47(0.22-0.72)$ & $1.2(1.0-1.5)$ & 3.4 \\
\hline Social & $0-10$ & $3.6(3.2)$ & $3.9(3.3)$ & Ns & $0.65(0.45-0.79)$ & $0.65(0.45-0.84)$ & $1.5(1.2-1.9)$ & 4.2 \\
\hline Work & $0-10$ & $1.3(1.9)$ & $1.9(2.8)$ & Ns & $0.41(0.16-0.62)$ & $0.41(0.0-0.81)$ & $1.8(1.4-2.3)$ & 5.2 \\
\hline Social and work disability & $0-10$ & $2.4(2.1)$ & $2.9(2.7)$ & Ns & $0.57(0.34-0.73)$ & $0.57(0.35-0.80)$ & $1.6(1.2-1.9)$ & 4.4 \\
\hline COMI score & $0-10$ & $4.5(1.5)$ & $4.6(1.7)$ & Ns & $0.63(0.42-0.77)$ & & $1.0(0.8-1.2)$ & 2.8 \\
\hline
\end{tabular}

$T 1$ Test one, $T 2$ Test 2, SEM standard error of measurement, $M D C$ minimal detectable change 
explained by their evaluation of a surgical population [12] Even if consistently showing a higher ceiling effect, this specific question is considered to add valuable information and should therefore continue to be part of the COMI $[4,5]$. The ceiling effect of $54 \%$ for work disability is in keeping with the fact that our cohort was only moderately disabled (ODI 30 , SD 17); more than $50 \%$ were still at work and only $12 \%$ were sick listed.

\section{Construct validity}

In line with previous validation studies, the composite COMI score as well as the scores for each of the separate COMI items correlated to at least some extent with the full scores of the reference scales, the ODI [24] and the EQ5D [25]. The COMI composite score showed a strong correlation with the full scores for the reference scales (ODI, $r=0.72$; EQ5D, $r=-0.73$ ). The correlation with ODI concurs with the findings of some previous studies, including those evaluating Brazilian Portuguese (0.64) [8], Chinese (0.69) [9], Hungarian (0.83) [12], and Korean (0.83) [15] versions of the COMI. The correlation with EQ5D also concurs with some previous studies [11, 13-15]

Our hypotheses of a moderate correlation between each of the COMI items and the composite reference scales were confirmed, with correlation coefficients ranging from 0.41 to 0.73 , with the exception of that for back pain, which had a lower correlation with ODI $(r=0.33)$. This might be considered odd as the ODI is considered a back pain related disability instrument. However, this was not evident when the higher of the pain score was used; then the relationship was stronger $(r=0.60)$. Further, the item Symptom-specific well-being showed lower correlations with the ODI full scale $(r=0.41)$ and with the EQ5D $(r=-0.46)$ in the present study. This concurs with previous studies also showing lower correlations for this specific item either measured with the ODI (Polish 0.43 [17], Hungarian 0.44 [12], Chinese 0.45 [9]) or the EQ5D (French 0.36 [11], Norwegian 0.43 [16].

\section{Reproducibility}

For analyzing test-retest reproducibility, 49 participants from the primary care cohort filled in the COMI twice with 7 days in-between. We considered this a reasonable period as $7-10$ days previously has been recommended [23]. We reached a fair to good reliability for the specific COMI items (ICC 0.41-0.78, Kappa $W$ 0.41-0.77). The COMI composite score showed good reliability (ICC 0.63 ) but was somewhat lower than that reported in previous studies (French 0.85 [11]; Italian 0.92 [13], Norwegian 0.89 [16];
Brazilian-Portuguese; 0.91 [8] and Chinese 0.91 [9]). The ICC is dependent on the variance between and within the subjects. Our data, compared with previous studies $[8,15$, 17], showed a lower COMI score (mean) at both $\mathrm{T} 1$ and $\mathrm{T} 2$ and a slightly narrower variance, which might have affected the ICC value (Table 3).

For a test retest design the item measured over time should be stable, to avoid bias [23]. We did not use a transition question between the tests as the time interval was only 7 days and no treatment was scheduled during this week. Even so, we cannot rule out the possibility that patients' symptoms were not sufficiently stable between the tests, and that there was indeed real change between them, which would have influenced the reproducibility statistics. However, looking into the differences between the tests in response to each domain on the COMI, only back function fell short of the recommended $90 \%$ of \pm 1 category ( 6 out of $49,12 \%)$ [30].

Our participants filled in the COMI and the reference scales at the clinic on the first occasion and at home on the second, prompted by a text-message. This methodology has successfully been used before [31]. The different environments in which the COMI was completed might however have influenced the stability of the data. Encouragingly, there were no significant differences in the mean scores on the two test occasions for back pain, leg pain, the other specific COMI domains and the COMI score. Our SEM (1.0), and hence MDC (2.8), was somewhat higher than reported in some of the previous COMI studies [5, 9, 17]. Our results are still in line with the Norwegian (MDC 2.2) [16] and not far from the French (MDC 2.0) [11] studies. Our MDC for the COMI score indicates that a change of 2.8 points or more gives a 95\% likelihood that it is a result of "real change" in the patient's condition instead of a measurement error. Based on previous COMI studies, the estimated minimal clinically important difference for the COMI summary score is between 2 and 3 [32].

\section{Strengths and limitations}

A strength of our study is that we followed strict guidelines in the cross-cultural adaptation and validation processes. Another strength is that we included participants from both primary and secondary care to increase the validity of the COMI in a Swedish context. Some limitations however need to be considered. As our patients were not highly disabled compared with those included in some of the previous validation studies, our results can only be generalized to a population like ours. Even so, our study included a diverse sample of patients with and without leg 
pain (51\% without leg pain) and from both primary (60\%) and secondary care.

The COMI covers several domains in one short, easy to complete instrument. Short instruments are warranted and useful for clinical and research purposes. A recent study by Osthols et al. [33] who surveyed physiotherapists in Sweden concluded that few PROMs are currently used in the everyday work of primary care physiotherapists, and at a low frequency, and one reason given for this is lack of time. We therefore find that to present the COMI in a Swedish context is important.

The Swedish COMI shows acceptable psychometric properties and may thus be suitable to use as a short instrument, measuring important domains in patients suffering from low-back pain with and without leg pain. Future studies should further evaluate its sensitivity to measure change in response to treatment.

Acknowledgements Open access funding provided by Karolinska Institute. We thank all participating physiotherapists and the patients for their contribution. We thank Riccardo Lo Martire for statistical support

\section{Compliance with ethical standards}

Conflict of interest None declared.

Ethical approval This study was approved by Stockholm's Regional Committee for Medical Research Ethics and was conformed to the declaration of Helsinki.

Informed consent All participants received oral and written study information and signed an informed consent.

Open Access This article is licensed under a Creative Commons Attribution 4.0 International License, which permits use, sharing, adaptation, distribution and reproduction in any medium or format, as long as you give appropriate credit to the original author(s) and the source, provide a link to the Creative Commons licence, and indicate if changes were made. The images or other third party material in this article are included in the article's Creative Commons licence, unless indicated otherwise in a credit line to the material. If material is not included in the article's Creative Commons licence and your intended use is not permitted by statutory regulation or exceeds the permitted use, you will need to obtain permission directly from the copyright holder. To view a copy of this licence, visit http://creativecommons.org/licenses/by/4.0/.

\section{References}

1. Hoy D, March L, Brooks P, Woolf A, Blyth F, Vos T, Buchbinder R (2010) Measuring the global burden of low back pain. Best Pract Res Clin Rheumatol 24(2):155-165. https://doi. org/10.1016/j.berh.2009.11.002

2. Bombardier C (2000) Outcome assessments in the evaluation of treatment of spinal disorders: summary and general recommendations. Spine (Phila Pa 1976) 25(24):3100-3103.
3. Deyo RA, Battie M, Beurskens AJ, Bombardier C, Croft P, Koes B, Malmivaara A, Roland M, Von Korff M, Waddell G (1998) Outcome measures for low back pain research. A proposal for standardized use. Spine (Phila Pa 1976) 23(18):2003-2013.

4. Ferrer M, Pellise F, Escudero O, Alvarez L, Pont A, Alonso J, Deyo R (2006) Validation of a minimum outcome core set in the evaluation of patients with back pain. Spine (Phila Pa 1976) 31 (12):1372-1379; discussion 1380. https://doi.org/10.1097/01. brs.0000218477.53318.bcdoi:

5. Mannion AF, Elfering A, Staerkle R, Junge A, Grob D, Semmer NK, Jacobshagen N, Dvorak J, Boos N (2005) Outcome assessment in low back pain: how low can you go? Eur Spine J 14(10):1014-1026. https://doi.org/10.1007/s00586-005-0911-9

6. Mannion AF, Porchet F, Kleinstuck FS, Lattig F, Jeszenszky D, Bartanusz V, Dvorak J, Grob D (2009) The quality of spine surgery from the patient's perspective. Part 1: the Core Outcome Measures Index in clinical practice. Eur Spine J 18(Suppl 3), 367-373. doi:10.1007/s00586-009-0942-8.

7. Mannion AF, Vila-Casademunt A, Domingo-Sabat M, Wunderlin S, Pellise F, Bago J, Acaroglu E, Alanay A, Perez-Grueso FS, Obeid I, Kleinstuck FS, European Spine Study G (2016) The Core Outcome Measures Index (COMI) is a responsive instrument for assessing the outcome of treatment for adult spinal deformity. Eur Spine J 25(8):2638-2648. https://doi.org/10.1007/s0058 6-015-4292-4

8. Damasceno LH, Rocha PA, Barbosa ES, Barros CA, Canto FT, Defino HL, Mannion AF (2012) Cross-cultural adaptation and assessment of the reliability and validity of the Core Outcome Measures Index (COMI) for the Brazilian-Portuguese language. Eur Spine J 21(7):1273-1282. https://doi.org/10.1007/s0058 6-011-2100-3

9. Qiao J, Zhu F, Zhu Z, Xu L, Wang B, Yu Y, Qian BP, Ding Y, Qiu Y (2013) Validation of the Simplified Chinese version of the Core Outcome Measures Index (COMI). Eur Spine J 22(12):28212826. https://doi.org/10.1007/s00586-013-2761-1

10. Cedraschi C, Marty M, Courvoisier DS, Foltz V, Mahieu G, Demoulin C, Gierasimowicz Fontana A, Norberg M, de Goumoens P, Rozenberg S, Genevay S, Rachis S, de la Societe Francaise de R, (2016) Core Outcome Measure Index for low back patients: do we miss anxiety and depression? Eur Spine J 25(1):265-274. https://doi.org/10.1007/s00586-015-3935-9

11. Genevay S, Cedraschi C, Marty M, Rozenberg S, De Goumoens P, Faundez A, Balague F, Porchet F, Mannion AF (2012) Reliability and validity of the cross-culturally adapted French version of the Core Outcome Measures Index (COMI) in patients with low back pain. Eur Spine J 21(1):130-137. https://doi.org/10.1007/s0058 6-011-1992-2

12. Klemencsics I, Lazary A, Valasek T, Szoverfi Z, Bozsodi A, Eltes P, Fekete TF, Varga PP (2016) Cross-cultural adaptation and validation of the Hungarian version of the Core Outcome Measures Index for the back (COMI Back). Eur Spine J 25(1):257-264. https://doi.org/10.1007/s00586-014-3750-8

13. Mannion AF, Boneschi M, Teli M, Luca A, Zaina F, Negrini S, Schulz PJ (2012) Reliability and validity of the cross-culturally adapted Italian version of the Core Outcome Measures Index. Eur Spine J 21(Suppl 6):S737-749. https://doi.org/10.1007/s0058 6-011-1741-6

14. Matsudaira K, Oka H, Oshima Y, Chikuda H, Taniguchi Y, Matsubayashi Y, Kawaguchi M, Sato E, Murano H, Laurent T, Tanaka S, Mannion AF (2018) Development of the Japanese Core Outcome Measures Index (COMI): cross-cultural adaptation and psychometric validation. BMC Musculoskelet Disord 19(1):71. https://doi.org/10.1186/s12891-018-1986-X

15. Kim HJ, Yeom JS, Nam Y, Lee NK, Heo YW, Lee SY, Park J, Chang BS, Lee CK, Chun HJ, Mannion AF (2018) Validation and cross-cultural adaptation of the Korean version of the Core 
Outcome Measures Index in patients with degenerative lumbar disease. Eur Spine J 27(11):2804-2813. https://doi.org/10.1007/ s00586-018-5759-x

16. Storheim K, Brox JI, Lochting I, Werner EL, Grotle M (2012) Cross-cultural adaptation and validation of the Norwegian version of the Core Outcome Measures Index for low back pain. Eur Spine J 21(12):2539-2549. https://doi.org/10.1007/s00586-012-2393-x

17. Miekisiak G, Kollataj M, Dobrogowski J, Kloc W, Libionka W, Banach M, Latka D, Sobolewski T, Sulewski A, Nowakowski A, Kiwic G, Pala A, Potaczek T (2013) Cross-cultural adaptation and validation of the Polish version of the core outcome measures index for low back pain. Eur Spine J 22(5):995-1001. https://doi. org/10.1007/s00586-012-2607-2

18. Kleinstueck FS, Fekete T, Jeszenszky D, Mannion AF, Grob D, Lattig F, Mutter U, Porchet F (2011) The outcome of decompression surgery for lumbar herniated disc is influenced by the level of concomitant preoperative low back pain. Eur Spine J 20(7):11661173. https://doi.org/10.1007/s00586-010-1670-9

19. Lattig F, Grob D, Kleinstueck FS, Porchet F, Jeszenszky D, Bartanusz V, O'Riordan D, Mannion AF (2009) Ratings of global outcome at the first post-operative assessment after spinal surgery: how often do the surgeon and patient agree? Eur Spine J 18(Suppl 3):386-394. https://doi.org/10.1007/s00586-009-1028-3

20. Sobottke R, Rollinghoff M, Zarghooni K, Zarghooni K, SchluterBrust K, Delank KS, Seifert H, Zweig T, Eysel P (2010) Spondylodiscitis in the elderly patient: clinical mid-term results and quality of life. Arch Orthop Trauma Surg 130(9):1083-1091. https ://doi.org/10.1007/s00402-009-0972-z

21. Zweig T, Mannion AF, Grob D, Melloh M, Munting E, Tuschel A, Aebi M, Roder C (2009) How to Tango: a manual for implementing Spine Tango. Eur Spine J 18(Suppl 3):312-320. https://doi. org/10.1007/s00586-009-1074-x

22. Beaton DE, Bombardier C, Guillemin F, Ferraz MB (2000) Guidelines for the process of cross-cultural adaptation of self-report measures. Spine(Phila Pa 1976) 25 (24):3186-3191.

23. Terwee CB, Bot SD, de Boer MR, van der Windt DA, Knol DL, Dekker J, Bouter LM, de Vet HC (2007) Quality criteria were proposed for measurement properties of health status questionnaires. J Clin Epidemiol 60(1):34-42. https://doi.org/10.1016/j. jclinepi.2006.03.012

\section{Affiliations}

\section{Hannah Granström ${ }^{1} \cdot$ Anna Langborg $^{1}$ - Anne F. Mannion ${ }^{3} \cdot$ Eva Rasmussen-Barr $^{1,2}$ iD}

1 Department of Neurobiology, Caring Sciences, and Society, Division of Physiotherapy, Karolinska Institutet, 14483 Huddinge, Sweden

2 Institute of Environmental Medicine, Karolinska Institutet, Box 210, 17177 Stockholm, Sweden
24. Fairbank J (2000) Revised Oswestry Disability questionnaire. Spine(Phila Pa 1976) 25 (19):2552.

25. EuroQol G (1990) EuroQol-a new facility for the measurement of health-related quality of life. Health Policy 16(3):199-208

26. McHorney CA, Tarlov AR (1995) Individual-patient monitoring in clinical practice: are available health status surveys adequate? Qual Life Res 4(4):293-307

27. Shrout PE, Fleiss JL (1979) Intraclass correlations: uses in assessing rater reliability. Psychol Bull 86(2):420-428

28. Landis JR, Koch GG (1977) The measurement of observer agreement for categorical data. Biometrics 33(1):159-174

29. Lo Martire R (2017) Reliability Coefficients. R package version $1(3): 1$

30. Nevill AM, Lane AM, Kilgour LJ, Bowes N, Whyte GP (2001) Stability of psychometric questionnaires. J Sports Sci 19(4):273278. https://doi.org/10.1080/026404101750158358

31. Lo Martire R, Lis A, Skillgate E, Rasmussen-Barr E (2017) Psychometric properties of the Swedish version of the Treatment Outcome Satisfaction Questionnaire. Eur Spine J 26(2):316-323. https://doi.org/10.1007/s00586-016-4876-7

32. Mannion AF, Porchet F, Kleinstuck FS, Lattig F, Jeszenszky D, Bartanusz V, Dvorak J, Grob D (2009) The quality of spine surgery from the patient's perspective: part 2. Minimal clinically important difference for improvement and deterioration as measured with the Core Outcome Measures Index. Eur Spine J 18(Suppl 3), 374-379. doi:10.1007/s00586-009-0931-y.

33. Osthols S, Bostrom C, Rasmussen-Barr E (2019) Clinical assessment and patient-reported outcome measures in low-back paina survey among primary health care physiotherapists. Disabil Rehabil 41(20):2459-2467. https://doi.org/10.1080/09638 288.2018.1467503

Publisher's Note Springer Nature remains neutral with regard to jurisdictional claims in published maps and institutional affiliations.
3 Department of Teaching, Research and Development, Spine Center Division, Schulthess Klinik, Lengghalde 2, 8008 Zurich, Switzerland 